\title{
A experiência vivenciada pelo familiar do paciente crítico em isolamento de contato
}

\section{The experience of the critical patient's relative in contact isolation}

\section{La experiencia vivenciada por el familiar del paciente crítico en aislamiento de contacto}

\author{
Lorena Guimarães Oliveira (iD \\ Universidade de Fortaleza - Fortaleza (CE) - Brasil
}

\author{
Gabriela Nunes Monteiro iD \\ Universidade de Fortaleza - Fortaleza (CE) - Brasil
}

Vanessa Leitão Azevedo

Universidade de Fortaleza - Fortaleza (CE) - Brasil

Prefeitura de Fortaleza - Fortaleza (CE) - Brasil

\section{Aglauvanir Soares Barbosa iD \\ Universidade da Integração Internacional da Lusofonia Afro-Brasileira - Redenção (CE) - Brasil Hospital Geral de Fortaleza - Fortaleza (CE) - Brasil}

\section{Celi Melo Girão iD}

Hospital Geral de Fortaleza - Fortaleza (CE) - Brasil

\section{Rita Mônica Borges Studart iD}

Universidade de Fortaleza - Fortaleza (CE) - Brasil

Hospital Geral de Fortaleza - Fortaleza (CE) - Brasil

\section{RESUMO}

Objetivo: Descrever a experiência vivenciada pelo familiar de paciente crítico em isolamento de contato. Métodos: Estudo com metodologia qualitativa, realizado em 2019, em uma unidade de transplante de uma instituição hospitalar pública, em Fortaleza, Ceará, Brasil, cujos participantes foram 17 familiares de pacientes que se encontravam internados na Unidade Pós-operatória de Alta Complexidade em isolamento de contato. A coleta de dados ocorreu por meio de entrevista semiestruturada, sendo realizada a análise temática, a partir da qual emergiram três categorias: A experiência do familiar no momento da visita; A fé como suporte para o enfrentamento na espera da recuperação do seu familiar; Os sentimentos vivenciados pela necessidade de isolamento. Resultados: Os achados revelaram a necessidade da precaução por isolamento, que assusta muito os familiares, e a importância do uso de aparelhos, de medidas de prevenção e de proteção, contexto em que a fé e a esperança acabam dando vez para o desânimo e tristeza. O medo do desconhecido e de contrair a doença de seu familiar traz um sentimento ambíguo. Conclusão: Percebeu-se nas falas que a religião, espiritualidade, crença, tem papel fundamental no dia a dia dos familiares e na recuperação dos pacientes em hospitalização, trazendo mais segurança e força em todo processo. A reação dos entrevistados diante da necessidade da utilização de equipamento de proteção individual, tanto pelos profissionais como por eles mesmos no período da visita, mostrou que foi interpretada como "nojo" para tocar em seus familiares.

Descritores: Enfermagem; Isolamento de Pacientes; Resultados de Cuidados Críticos.

\section{ABSTRACT}

Objective: To describe the experience of a family member of a critical patient in contact isolation. Methods: This is a qualitative study, carried out in 2019, in a transplant unit of a public hospital in Fortaleza, Ceará, Brazil, whose participants were 17 relatives of patients who were hospitalized in the High Complexity Postoperative Unit in contact isolation. Data collection took place through semi-structured interviews, with thematic analysis being carried out, from which three categories emerged: The family member's experience at the time of the visit; Faith as support for coping while waiting for your family member to recover; and The feelings experienced by the need for isolation. Results: The findings revealed the need for precaution for isolation, which greatly scares family members and the importance of using devices, preventive and protective measures, a context in which faith and hope end up giving way to discouragement and sadness. The fear of the unknown and of contracting the illness of your relative brings

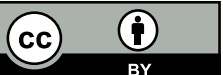


an ambiguous feeling. Conclusion: It was perceived in the statements that religion, spirituality, and belief have a fundamental role in the daily lives of family members and the recovery of patients in hospitalization, bringing more security and strength in the whole process.

Descriptors: Nursing; Patient Isolation; Critical Care Outcomes.

\section{RESUMEN}

Objetivo: Describir la experiencia vivenciada por el familiar de paciente critico en aislamiento de contacto. Métodos: Estudio con metodología cualitativa realizado en 2019 en una unidad de trasplante de una institución hospitalaria pública de Fortaleza, Ceará, Brasil, cuyos participantes fueron 17 familiares de pacientes ingresados en la unidad postoperatoria de alta complejidad de aislamiento de contacto. La recogida de datos se dio a través de entrevista semiestructurada y se realizó el análisis temático de lo cual emergieron tres categorías: La experiencia del familiar durante la visita; El apoyo de la fe para el afrontamiento de la espera de la recuperación de su familiar; Los sentimientos vividos debido el aislamiento. Resultados: Los hallazgos revelaron la necesidad de precaución por el aislamiento que asusta mucho los familiares y la importancia del uso de aparatos, de medidas de prevención e de protección, contexto en el cual se cambia la fe y la esperanza por el desánimo y la tristeza. El miedo del desconocido y de tener la enfermedad de su familiar lleva a un sentimiento ambiguo. Conclusión: Se percibió en las hablas que la religión, la espiritualidad y la creencia tienen el papel fundamental en el cotidiano de los familiares y para la recuperación de los pacientes ingresados que tienen más seguridad y fuerza en todo el proceso. La reacción de los entrevistados ante la necesidad de la utilización de aparato de protección individual por los profesionales y por ellos mismos durante la visita ha sido interpretada como "aversión" de tocar sus familiares.

Descriptores: Enfermería; Aislamiento de Pacientes; Resultados de Cuidados Críticos.

\section{INTRODUÇÃO}

A doença que leva a uma internação hospitalar conta com aspectos de ordem física e psicológica que fragilizam pacientes e familiares, ocorrendo, ao mesmo tempo, uma desestruturação do desenho familiar e uma desconstrução dos conceitos conhecidos ${ }^{(1,2)}$. Instigados pela angústia de morte que costuma aparecer nesses momentos, o paciente crítico, assim como sua família, se depara com dificuldades no enfrentamento da situação de adoecimento(3).

A colocação de pacientes hospitalizados em isolamento é feita para proteger o paciente imunocomprometido de outros (isolamento reverso) ou para proteger outros do processo infeccioso do paciente (isolamento) ${ }^{(4)}$. Ambas as situações exigem a limitação do contato para impedir a propagação de patógenos, pois as infecções relacionadas à assistência à saúde (IRAS) apresentam impacto sobre letalidade, internação, custos e surgimento de resistência antimicrobiana, o que confere às IRAS especial relevância para a saúde pública( ${ }^{(5)}$.

Nesse direcionamento, faz parte do tratamento, além de fármacos, medidas de precaução de contato utilizadas para a prevenção da disseminação de microrganismos de importância epidemiológica( ${ }^{(6)}$. Entre as principais medidas de precaução de contato nos pacientes detectados com microrganismos multidroga resistentes, estão: a higienização das mãos, o uso constante do avental e luvas e o isolamento do paciente ${ }^{(7)}$.

A situação da família se constitui em estresse permanente, sofrimento interno, elevação de ansiedade, medo do desconhecido e apreensão quanto às decisões a tomar e situações a enfrentar. Entre $25 \%$ a $50 \%$ dos familiares de pacientes críticos experimentam sintomas psicológicos, incluindo estresse agudo, estresse póstraumático, ansiedade generalizada e depressão(8).

O processo de hospitalização pode acarretar, ainda, um sentimento ambíguo de compaixão e gratidão com fragilidade e medo, pois, para realização de um tratamento efetivo no paciente crítico, são necessários inúmeros procedimentos invasivos, bem como a utilização de um arsenal tecnológico que assusta e causa impacto negativo no familiar, podendo gerar apreensão, desespero e impotência ${ }^{(9)}$.

Quando um paciente internado em terapia intensiva se encontra em isolamento de contato, gera uma situação de crise, na qual o indivíduo se depara com o incontrolável e com a condição humana frágil. A informação sobre a necessidade de isolamento de contato é oferecida aos familiares quando se tem o resultado bacteriológico positivo ou quando ele é transferido de outra instituição( ${ }^{(10)}$. Nesse contexto, são utilizadas técnicas e equipamentos como meio de evitar a propagação de micro-organismos no ambiente hospitalar, que se denomina precaução de contato(11).

Além desses relevantes aspectos, o isolamento de contato simboliza um ataque à estrutura da personalidade familiar, além de designar uma crise acidental na vida do ser humano. O familiar observa e analisa o modo como a equipe de saúde assiste seu ente querido no bloqueio de disseminação dessas infecções no meio hospitalar e inúmeros pensamentos permeiam sua mente no imensurável mundo do desconhecido contato ${ }^{(12)}$. 
O entendimento sobre a experiência vivenciada e os sentimentos apresentados pelos familiares do paciente crítico em isolamento de contato certamente preencherá uma lacuna importante para promoção da saúde nesse contexto, melhorando os cuidados à família, com redução do medo e da ansiedade, além de sensibilizar os familiares na questão de bloqueio de disseminação dessas infecções de contato ${ }^{(13)}$.

Nessa perspectiva, a Política Nacional de Promoção da Saúde (PNPS), revisada em 2014, tem como um dos temas transversais a produção de saúde e cuidado, que concebe agregar o tema em redes que propiciem práticas de cuidado humanizadas, que promovam o diálogo, erguendo práticas pautadas na integralidade do cuidado e da saúde ${ }^{(14)}$. Desse modo, o cuidado relacionado ao isolamento deve conter aspectos de inclusão familiar na perspectiva da clínica ampliada e da corresponsabilização do cuidado para prevenção de agravos, promoção da saúde e reabilitação(15).

Assim, questiona-se, como o familiar vivencia a experiência e os sentimentos no momento da visita ao seu familiar que se encontra em isolamento de contato. Portanto, o objetivo deste estudo foi descrever a experiência e os sentimentos vivenciados pelo familiar do paciente crítico em isolamento de contato.

\section{MÉTODOS}

Estudo exploratório e qualitativo caracterizado pela investigação de crenças, percepções e opiniões que resultam da interpretação humana acerca de suas vivências e sentimentos ${ }^{(16)}$. A pesquisa ocorreu na Unidade de Transplante do Hospital Geral de Fortaleza, em Fortaleza, Ceará, Brasil, considerado o maior hospital público da rede estadual, sendo referência para o nível terciário em transplantes renais, córneas, neurocirurgia, ortopedia, cirurgia vascular, neurologia, oftalmologia, reumatologia, nefrologia e obstetrícia de alto risco(17).

Para a visita dos familiares nessa unidade, é destinado um período de 60 minutos, no turno da tarde, sendo esse momento acompanhado por enfermeiro e outros profissionais que compõem a equipe de saúde da unidade.

Realizou-se o convite aos familiares no momento da visita, mediante convite formal pelos pesquisadores, que explicaram a cada um o objetivo do estudo. Selecionou-se a amostra à medida que seus parentes entravam em isolamento de contato, sendo excluídos familiares com parentesco de quarto grau, em razão do distanciamento afetivo, e os familiares de crianças, pela especificidade dessa população. Assim, compuseram a amostra 17 familiares de pacientes internados que se encontravam em isolamento de contato.

A coleta de dados ocorreu de agosto a setembro de 2019, por meio de entrevista semiestruturada gravada individualmente após o momento da visita, para preservar a individualidade e singularidade do participante. A escolha pelo desenvolvimento dessa técnica neste estudo deu-se pela possibilidade de coletar dados subjetivos, próprios de pesquisa qualitativa, relacionados aos valores, atitudes e opiniões dos entrevistados, dados que não poderiam ser obtidos por meio de um questionário ${ }^{(18)}$.

O roteiro da entrevista foi dividido em duas etapas: na primeira eram obtidos os dados pessoais, como idade, sexo, procedência, escolaridade, estado civil, renda familiar e parentesco, e a segunda consistia em uma questão norteadora para descrever a experiência vivenciada pelo familiar do paciente crítico em isolamento de contato: como você descreve sua experiência e seus sentimentos no momento da visita ao seu familiar que se encontra em isolamento de contato?

As entrevistas ocorreram individualmente, em um clima de cordialidade entre entrevistador e entrevistado, em sala reservada no próprio serviço de saúde, com duração de 20 minutos cada, sendo gravadas em mp3 para assegurar um material fidedigno para análise. O encerramento amostral se deu quando se alcançou o objetivo da pesquisa, levando-se em consideração o critério de saturação temática ${ }^{(19)}$. Posteriormente, realizou-se a transcrição de todas as entrevistas em um programa de edição de textos.

Para a sistematização e análise dos dados, utilizou-se a análise de conteúdo, especificamente a análise temática, que consiste em um conjunto de técnicas de análise das comunicações visando obter, por procedimentos sistemáticos e objetivos de descrição do conteúdo das mensagens, indicadores que permitam a inferência de conhecimentos relativos às situações ${ }^{(20)}$. Analisaram-se os depoimentos de forma exaustiva na tentativa de levantar indicadores que levassem à inferência acerca da temática pesquisada. Em consequência do quantitativo de falas dos entrevistados, a análise procedeu através de uma série de procedimentos estatísticos com a finalidade de correlacionar o contexto linguístico e as categorias dos grupos pertinentes às falas dos entrevistados. Posteriormente, processaram-se as análises do conteúdo das entrevistas no software IRAMUTEQ ${ }^{(21)}$, retendo-se na classificação hierárquica descendente.

Gerou-se um leque semântico a partir da retenção das palavras pela análise de similitude, na qual se identifica a conexão entre as palavras contidas no corpus e entre elas, destacando-se as palavras: "isolamento", "fé", 
"enfrentamento", "familiar" e "visita", todas interligadas entre si, sendo a palavra "isolamento" localizado no ponto central, que possui a maior quantidade de conexões. Desse modo, pôde-se inferir sobre as análises categóricas a partir das relações de afinidade entre as classes, emergindo três categorias: a fé como suporte para o enfrentamento na espera da recuperação do seu familiar; a experiência no momento da visita; os sentimentos vivenciados pela necessidade de isolamento.

A pesquisa faz parte de um projeto guarda-chuva em busca de subsídios para a construção de tecnologias educacionais. Submeteu-se à apreciação do Comitê de Ética em Pesquisa do Hospital Geral de Fortaleza e obteve-se aprovação com o Parecer n. ${ }^{\circ}$ 2.435.893. Os participantes assinaram o Termo de Consentimento Livre e Esclarecido, sendo identificados pela letra "E", significando entrevistado, seguida de um número.

\section{RESULTADOS E DISCUSSÃO}

Neste espaço serão apresentados e discutidos os resultados do estudo. Inicialmente, os dados pessoais dos entrevistados e, em seguida, as categorias temáticas que surgiram do estudo.

\section{Dados pessoais dos entrevistados}

O estudo teve a amostra constituída por dezessete participantes, sendo dez do sexo masculino e sete do feminino. Com relação à idade, os indivíduos apresentavam de 23 a 56 anos. Em relação à procedência, sete eram de Fortaleza, dez eram de outros municípios do Ceará e de outros estados. Quanto ao grau de instrução, sete tinham o ensino fundamental, oito tinham o ensino médio e dois, ensino superior.

Com relação ao estado civil, doze eram solteiros e cinco casados (união estável). Sobre a renda familiar, apenas um relatou receita de três salários, havendo uma semelhança entre renda com um e dois salários. Quanto ao grau de parentesco, identificaram-se cinco filhos, três irmãos, três primos, dois tios, uma sobrinha, uma mãe, um pai e uma esposa.

\section{A fé como suporte para o enfrentamento na espera da recuperação do seu familiar}

Esta categoria remete ao sentimento frente à notícia do isolamento e a fé como suporte para enfrentar a recuperação do familiar. A preocupação com seu familiar, bem como a incerteza de resposta ao tratamento, é expressa com angústia e apego à religião para aliviar o sofrimento e os pensamentos ruins:

“[...] Eu sempre fui católica; acredito em Deus, sempre oro. Quando ela pegou essa infecção, rezei muito mais, e aqueles pensamentos ruins saíram da minha cabeça." (E4)

"Eu fico preocupada [...] Meu irmão está com um rim de outra pessoa e mais uma bactéria que não morre, me dá gastura [...] Mas o sofrimento da máquina era demais para ele. O jeito é rezar para ele ficar logo bom." (E8)

"[...] Nunca falto à missa, sempre faço minhas orações em casa e meus amigos sempre me falam que estou em suas orações. Tenho muita fé que ele vai ficar bom." (E2)

A fé e a religião como suporte para o enfrentamento na espera da recuperação do seu familiar surgem com ênfase quando o homem não encontra explicação lógica para a problemática que está vivenciando. Desse modo, novas formulações e novos significados dão sentido ao mundo dentro do contexto da fé(7).

O processo saúde-doença visto pela pessoa religiosa vai além da esfera investigada pelo médico. A doença surge como ruptura do equilíbrio, que não atinge somente o físico, mas inclui outras áreas que harmonizam o individuo (como bem-estar, trabalho, alimentação, conforto). As práticas religiosas trazem aos seus adeptos a explicação e a solução dos problemas ${ }^{(22)}$.

Um aspecto que religião e medicina partilham é o sofrimento. A medicina tem como objetivo aliviar o sofrimento, processo no qual não está só. O papel das famílias e de outros contatos sociais adquire importância ao providenciar significado ao sofrimento e à sua experiência moral. Essas razões são as mesmas que levam indivíduos em sofrimento e os seus a procurarem a religião, que terá como contribuição tornar o sofrimento mais suportável(23).

Assim, a religião é considerada um suporte familiar, no qual as esperanças são reconstituídas e, assim, o familiar pode pensar na melhora de seus entes:

"Faz uns dois dias que não sinto felicidade... Parece que minhas forças se acabaram, perdi a fé. Minha mãe esperou tanto por esse transplante e, agora, pegou essa bactéria resistente..." (E17)

"Não perdi a fé. [...] Temos que confiar que temos um ser maior, que é Jesus Cristo, Nossa Senhora, os santos, os anjos; confiar que nossas vidas estão nas mãos de Deus, que seja feita a vontade dele." (E2) 
Religião e fé são recursos utilizados com frequência, principalmente quando se trata de ambiente hospitalar. É comum ouvir frases como "se Deus quiser, vou melhorar, estou me sentindo melhor"; "Graças a Deus, é preciso ter fé em Deus para melhorar". Tais frases apontam para a relação da religião ou fé com otimismo, esperança de melhora, na busca de força num ser superior que possa auxiliar. Essa fé ajuda a enfrentar procedimentos invasivos, a alimentar-se mesmo quando não há apetite algum, como se a crença fosse que Deus já vai fazer sua parte, então cabe ao paciente cooperar e fazer a parte dele ${ }^{(24)}$. Os familiares têm na religião conforto e resposta para o que estão passando, pois a fé exerce um equilíbrio emocional importante e, com a espiritualidade, caracteriza-se como recurso poderoso para o fortalecimento dos vínculos familiares ${ }^{(25)}$.

\section{A experiência no momento da visita}

Esta categoria trata da experiência dos familiares no momento da visita. Cheios de incertezas, os familiares, ao fazerem suas visitas, se deparam com medidas cautelosas de proteção e, por falta de ensinamentos da importância do uso de adornos, classificam o comportamento dos profissionais como estranho, grosseiro ou nojo dos pacientes:

"Eu fiquei chocada quando me deram o avental, as luvas e a máscara. Fiquei preocupada. [...] Pensei logo que era algo muito sério, mas não tive coragem de perguntar." (E8)

"Gente, que horror essa visita! A enfermeira me mandando fazer um monte de coisa: lavar as mãos, colocar o avental, a máscara e as luvas... É minha mãe, entende? Fiquei com tanta raiva, nunca vou ter nojo dela e Deus não vai me deixar pegar essa infecção." (E16)

"[...] Aí me disseram que eu não podia pegar em nada, só se fosse de luva... Achei tudo muito estranho e grosseiro." (E6)

Para os visitantes investigados, havia um sentimento de medo e espanto quando eram abordados por profissionais para usarem o equipamento de proteção e quando viam seus parentes cheios de equipamentos de medicação e monitoramento, o que levou a analisar se eles realmente entendiam a necessidade de tudo aquilo, pois acompanhantes devem receber esclarecimentos acerca do que é a precaução de contato, com o intuito de estimular o seu engajamento, aumentar as chances de sucesso e reduzir as chances de eventos indesejados decorrentes da assistência.

O conhecimento adequado e atualizado sobre os aspectos relacionados à higienização das mãos e ao uso da proteção na precaução de contato auxilia o profissional de saúde diante da sua aplicabilidade no cenário de cuidado ${ }^{(26)}$.

O medo do desconhecido os acompanha durante as visitas. As bactérias, como assim são classificadas por eles, podem ser transmitidas para eles durante as visitas. Por outro lado, outros entrevistados dizem não ter medo de pegar doenças, pois se tratam de seus familiares:

"Fiquei impressionada com o tanto de soro e remédio que meu sobrinho estava tomando... Fiquei preocupada de não levar essa doença dele para meus filhos, Deus me perdoe..." (E13)

“[...] Achei muito estranha essa história de isolamento... Todos com 'nojo' da minha prima... Eu dei logo foi um beijo nela para mostrar que eu não estava com 'nojo.". (E12)

"Quando eu soube da bactéria, eu fiquei com medo de pegar. Mas aí já estava lá, na hora da visita, não disse nada... Passei o dia pensando e com medo de pegar essa doença dele." (E14)

"Deus me perdoe, mas fiquei com muito medo de pegar essa infecção... Me senti tão ruim. Meu pai e eu aqui com 'nojo' dele." (E15)

Como percebido, a palavra "nojo" foi apresentada em várias ocasiões. Provavelmente, ela expressa o distanciamento do profissional, quer dizer, a falta de humanização do cuidado e do acolhimento adequado à família pelos profissionais de saúde ${ }^{(27)}$. $\mathrm{O}$ isolamento de contato envolve não somente o usuário internado, mas também toda a família, que vivencia a hospitalização diariamente e que adoece muitas vezes psicologicamente pelo distanciamento imposto ${ }^{(28)}$.

Para a promoção da saúde, no momento de isolamento de um ente querido, o enfermeiro e os demais profissionais de saúde necessitam adicionar em seus cuidados a inclusão da família mediante acolhimento, escuta das suas necessidades e intervenções resolutivas ${ }^{(29)}$.

A família é um potente aliado da equipe de saúde, por isso conhecer suas características, necessidades e expectativas favorece uma assistência de qualidade, contemplando a humanização, a criação de vínculo e a comunicação, aspectos importantes para a promoção da saúde, com o cuidado centrado na família, já presente na Política Nacional de Atenção ao Paciente Crítico do Ministério da Saúde ${ }^{(30)}$. 
Alguns acompanhantes do presente estudo relataram de forma aterrorizada a forma como são abordados para a utilização do uso de equipamentos de proteção individual (EPI), pois não conseguem compreender porque devem se proteger ao entrar em contato com um familiar que amam tanto e do qual não sentem nojo. Independentemente do tipo de infecção, um conjunto de medidas devem ser adotadas para o atendimento de pacientes hospitalizados quando existir o risco de contato com sangue, líquidos corpóreos em geral, secreções e excreções, solução de continuidade da pele e mucosas ${ }^{(31)}$.

É necessário orientar os visitantes sobre o quadro clínico do paciente que está em isolamento. Explicar a utilização de equipamentos de proteção e as rotinas de higienização, mostrando de forma mais clara a necessidade de tudo aquilo, envolvendo-os no processo. Possibilitar a compreensão da condição de saúde e a convivência com a doença para que ocorra adesão aos cuidados e rotinas necessários à qualidade da assistência e prevenção das infecções hospitalares ${ }^{(32)}$.

Os profissionais da saúde devem conscientizar os familiares de que as medidas adotadas são fundamentais para que não haja a transmissão de bactérias/vírus, retirando a impressão de seu familiar estar sendo tratado com nojo. A transmissão por contato pele a pele e contato com superfícies ambientais está relacionada a: falhas no uso dos equipamentos de proteção individual, não lavagem das mãos, quebra de técnicas assépticas, entre outros fatores ${ }^{(33)}$.

Outro estudo mostra que o envolvimento dos acompanhantes no processo do cuidado em todos os níveis da assistência de saúde pode colaborar para o desempenho satisfatório dos profissionais no que concerne à segurança do paciente, sendo parceiros corresponsáveis do cuidado, principalmente em atividades ligadas à manutenção do ambiente seguro, como a higienização das mãos e o uso de equipamentos de proteção individual( ${ }^{(34)}$.

\section{Sentimentos vivenciados pela necessidade de isolamento.}

Esta categoria trata dos sentimentos dos familiares, a importância do uso de aparelhos, medidas de prevenção e proteção, contexto em que a fé e a esperança acabam dando vez para o desânimo e a tristeza:

"[...] Eu mesmo desanimei, várias vezes... Muito triste a situação, ver minha prima respirando por aparelhos... Chorei muito." (E9)

"Todas as noites eu pensava: será que amanhã ele vai ter alta? Será que vai ser depois? Aquela espera [...] dava aquela tristeza na gente, né? Perdi a esperança..." (E7)

Quando o paciente está internado, fatores como a distância, o não poder contribuir para sua melhora diretamente, a situação de incerteza, a possibilidade de morte e, em alguns casos, a ausência de resposta ao tratamento, ocasionam um sentimento de angústia e tristeza para a família ${ }^{(35)}$.

Nesta categoria, observou-se que os familiares, muitas vezes, ao se depararem com o isolamento de contato, preocupam-se apenas com a saúde de seu familiar, e não com o coletivo ali presente, sendo difícil interpretar por eles essas necessidades. Ao serem orientados pelos profissionais sobre as condutas necessárias, não acham que são um ganho, pois já são portadores de um germe multirresistente, demonstrando desconforto ao ter que usar uma barreira protetora, como avental e luvas ${ }^{(36)}$.

Por outro lado, os familiares, ao serem esclarecidos sobre o motivo do isolamento e uso de adornos para proteção dos pacientes, pensam diferente, acham o trabalho dos profissionais algo cuidadoso e organizado:

"Eles têm tanto do cuidado... Muito impressionante. Tudo para proteger a gente dessa infecção. Tem avental, luva e máscara para todos que visitam... Muito organizado." (E14)

"[...] Na terceira vez que fui visitar, já foi diferente. Outra enfermeira me explicou com muita delicadeza sobre a bactéria, achei muito importante e vi que eles não estavam com nojo, e sim com cuidado.” (E12)

Um estudo realizado sobre a prevenção de infecção cruzada entre acompanhantes e pacientes em ambiente hospitalar ${ }^{(37)}$ observou que a falta de informação transmitida deixam tanto o acompanhante quanto o paciente vulneráveis a adquirir e transmitir infecções hospitalares. Foram oferecidas informações aos acompanhantes do presente estudo, havendo boa receptividade e adesão, como lavagem das mãos, não acúmulo de objetos desnecessários e ausência de sinais e sintomas de infecções enquanto os pacientes continuam em internamento por isolamento de contato, pois o tratamento é longo e cauteloso para garantir a melhora e, finalmente, a alta.

À medida que os dias passam, a esperança diminui. Para o controle das infecções hospitalares, uma ação de enfermagem é o controle do fluxo de pessoas na Unidade de Terapia Intensiva (UTI), pois visitantes, familiares e 
demais profissionais da instituição podem ser potenciais fontes de transmissão. Uma importante ação adotada nas UTI é a vestimenta adequada e específica ${ }^{(37)}$.

Para realização de um tratamento efetivo, são necessários procedimentos, como punções, procedimentos invasivos, cateterismos, aspirações e todo um aparato tecnológico, podendo causar um impacto no familiar, assustando-o, pela falta de conhecimento. Se tudo isso não for aliado às explicações da equipe de saúde, pode gerar apreensão, desespero e impotência nos familiares ${ }^{(38)}$.

Quando, sem espera alguma, o paciente é diagnosticado com uma infecção que necessite de isolamento de contato, a notícia pode assustar muito os seus familiares. O medo do desconhecido, dessa bactéria muito forte, que faz com que seu familiar necessite de maiores cuidados, chega a provocar revolta:

"Passei muito tempo para entender essa situação... Fiquei revoltado quando soube que meu pai estava com uma infecção forte. Adianta saber quem foi o culpado? Não vai mudar nada... Estou muito triste, mas, na frente dele, dou a maior força, sabe?" (E1)

"[...] Quando o médico falou que meu pai estava com uma bactéria muito forte, meu chão caiu... Meu coração ficou acelerado... Nem acreditava numa notícia daquelas..." (E5)

Ao necessitar de precaução de contato, com resultados de cultura positivos, os profissionais devem orientar os acompanhantes no momento da visita. Caso contrário, essa atitude pode acarretar a ideia de que os pacientes devem ficar isolados do convívio de outras pessoas. Os acompanhantes, ao não serem instruídos, chegam a pensar na existência de algo grave ${ }^{(38)}$.

Reforça-se o impacto do estudo em questão para a Política Nacional de Promoção da Saúde (PNPS)(14), que objetiva promover o diálogo, ergue práticas pautadas na integralidade do cuidado e da saúde. No caso deste estudo, os profissionais devem, de forma humanizada, conscientizar os familiares sobre a importância do isolamento de seu paciente e a necessidade de utilização dos equipamentos de proteção individual no momento da visita na unidade de isolamento para a recuperação do seu paciente e proteção do familiar.

Dessa forma, a humanização perpassa a relação com a ética e o acolhimento dos familiares e pacientes, assim como o respeito aos seus direitos. Aparecerem dificuldades com os preceitos da Politica Nacional de Humanização para assegurar e executar as práticas assistenciais pautadas na humanização ${ }^{(39)}$, quando o profissional enfatiza mais a parte técnica, para não disseminar a contaminação do patógeno, do que o acolhimento ao familiar.

Ressalta-se que o atual estudo apresenta limitações, que incluem, principalmente, o fato de ter envolvido apenas familiares no momento da visita, o que dificultou a generalização dos resultados. Por fim, os achados sinalizam que o paciente e seu familiar devem ser acolhidos não somente nas suas necessidades biológicas, mas no uso da comunicação, sendo relevante como prática intimamente relacionada à humanização do cuidado.

Como a Política Nacional de Humanização tem o intuito de formar profissionais cuja prática deve ser pautada em ações com eficiência técnica, científica e humana, de forma ética, respeitando a individualidade do paciente e com olhar holístico, sugere-se a realização de cursos de aperfeiçoamento para toda a equipe desses profissionais, a fim de minimizar os problemas aqui detectados.

\section{CONSIDERAÇÕES FINAIS}

O estudo buscou identificar a percepção da experiência vivenciada pelo familiar do paciente crítico em isolamento de contato. Percebeu-se que a presença do familiar é indispensável, e que, muitas vezes, está tão fragilizado por toda a situação que acaba buscando na fé e na religião forças para continuar firme em todo o processo da doença e hospitalização de seu familiar.

Outro aspecto importante foi a reação dos entrevistados diante da necessidade de utilização dos equipamentos de proteção individual, tanto por parte dos profissionais como por eles mesmos no período da visita. Os familiares entenderam o isolamento como uma espécie de "nojo" por parte dos profissionais em relação ao seu ente querido.

Observaram-se sentimentos ambíguos entre medo de pegar a doença no momento da visita, agradecimento por tantos cuidados e revolta pela necessidade de isolamento.

\section{CONFLITOS DE INTERESSE}

Os autores declaram que não houve conflitos de interesses. 


\section{CONTRIBUIÇÕES}

Lorena Guimarães Oliveira, Gabriela Nunes Monteiro e Vanessa Leitão Azevedo contribuíram com a elaboração e delineamento do estudo; a aquisição, análise e interpretação de dados; a redação e/ou revisão do manuscrito. Rita Mônica Borges Studart contribuiu com a elaboração e delineamento do estudo; a redação e/ou revisão do manuscrito. Aglauvanir Soares Barbosa e Celi Melo Girão contribuíram com a redação e/ou revisão do manuscrito.

\section{REFERÊNCIAS}

1. Flach $\mathrm{K}$, Lobo BO, Potter JR, Lima NS. O luto antecipatório na unidade de terapia intensiva pediátrica: relato de experiência. Rev SBPH [Internet]. 2012 [acesso em 2020 Abr 9];15(1):83-100. Disponível em: http:// pepsic.bvsalud.org/scielo.php?script=sci_arttext\&pid=\$1516-08582012000100006

2. Ferreira PD, Mendes TN. Família em UTI: importância do suporte Psicológico diante da iminência de morte. Rev SBPH [Internet]. 2013 [acesso em 2020 Abr 9];16(1):88-112. Disponível em: http://pepsic.bvsalud. org/scielo.php?script=sci_arttext\&pid=S1516-08582013000100006

3. Padoveze MC, Figueiredo RM. The role of primary care in the prevention and control of healthcare associated infections. Rev Esc Enferm USP [Internet]. 2014 [acesso em 2020 Abr 9];48(6):1137-44. Disponível em: http:// www.scielo.br/pdf/reeusp/v48n6/0080-6234-reeusp-48-06-1137.pdf

4. World Health Organization. Guidelines on core omponentes of infection prevention and control programmes at the national and acute health care facility level [Internet]. Geneva: WHO; 2016 [acesso em 2020 Abr 10]. Disponivel em: http://www.who.int/gpsc/corecomponents.pdf

5. Moreira EKCB, Martins TM, Castro MM. Representação social da psicologia hospitalar para familiares de pacientes hospitalizados em unidade de Terapia Intensiva. Rev SBPH [Internet]. 2013 [acesso em 2020 Abr 9];15(1):134-67. Disponível em: http://pepsic.bvsalud.org/scielo.php?script=sci_arttext\&pid =S1516-08582012000100009

6. González-Estrada A, Fernández-Prada M, Martínez Ortega C, Lana Pérez A, López González ML. Cumplimiento de las precauciones de aislamiento de contacto por microorganismos multirresistentes en un hospital de tercer nível. Rev Calid Asist [Internet]. 2016 [acesso em 2020 Abr 9];31(5):293-99. Disponível em: http://eduem.uem.br/ojs/index.php/CiencCuidSa ude/article/view/15204/pdf

7. Mellagi AG. O enfrentamento religioso em pacientes portadores de HIVIAIDS: um estudo psicossocial entre homens católicos e evangélicos. São Paulo: Universidade de São Paulo; 2009.

8. Rabelo AHS, Sousa TV. O conhecimento do familiar/acompanhante acerca da precaução de contato: contribuições para enfermagem pediátrica. Esc Anna Nery Rev Enferm [Internet]. 2009 [acesso em 2020 Abr 9];2(3). Disponível em: http://www.scielo.br/pdf/ean/v13n2/v13n2a06.pdf

9. Rodrigues MP, Lima KC, Roncalli AGA. Representação social do cuidado no programa saúde da família na cidade de Natal. Ciênc Saúde Colet [Internet]. 2018 [acesso em 2020 Abr 9];13(1):71-82. Disponível em: http://www.scielo.br/scielo.php?pid=S1413-81232008000100012\&script=sci_abstract\&tlng=pt

10. Matos MCB, Matosa JGNF, Sousa LRM, Sousa AFL, Queiroz AAFLN, Moura MEB. Infection Control is a Safety Indication": discussions based on the student's perspective. J Res Fundam Care [Internet]. 2018 [acesso em 2020 Abr 9];10(3):640-6. Disponível em: http://www.seer.unirio.br/index.php/cuidadofundamental/ article/view/6137

11. Souza ES, Belei RA, Carrilho CMDM, Matsuo T, Yamada-Ogatta SF, Andrade G, et al. Mortality and risks related to healthcareassociated infection. Texto \& Contexto Enferm [Internet]. 2015 [acesso em 2020 Abr 9];24(1):220-8. Disponível em: http://www.scielo.br/scielo.php?script=sci_arttext\&pid =S0104-07072015000100220

12. Kotkowski KA, Ellison RT, Barysaus CM, Barton BA, Allison JJ, Mack DA, et al. Association of hospital contact precaution policies with emergency department admission time. J Hosp Infect [Internet]. 2017 [acesso em 2020 Abr 9];96(3):244-9. Disponível em: https://www.ncbi.nlm.nih.gov/pubmed/28454768

13. Padilha JMFO, Sá SPC, Silvino ZR. Gloves and nursing professionals' adherence to contact precautions: an 
integrating review. J Nurs UFPE [Internet]. 2017 [acesso em 2020 Abr 9];11(2):667-74. Disponível em: https:// pdfs.semanticscholar.org/6bf4/e1e31decbfde587a57637e9d51b64b6da9f9.pdf

14. Ministério da Saúde (BR), Secretaria de Vigilância em Saúde; Secretaria de Atenção à Saúde. Portaria $n^{\circ}$ 2.446, de 11 de novembro de 2014 [Internet]. Redefine a Política Nacional de Promoção da Saúde (PNPS). Brasília: Ministério da Saúde; 2014 [acesso em 2020 Abr 15]. Disponível em: https://bvsms.saude.gov.br/bvs/ saudelegis/gm/2014/prt2446_11_11_2014.html

15. Malta DC, Reis AAC, Jaime PC, Morais OL Neto, Silva MMA, Akerman M. Brazil's Unified Health System and the National Health Promotion Policy: prospects, results, progress and challenges in times of crisis. Ciênc Saúde Colet. 2018;23(6):1799-809.

16. Minayo MCS. O desafio do conhecimento: pesquisa qualitativa em saúde. 14a ed. São Paulo: Hucitec; 2014.

17. Hospital Geral de Fortaleza. Acesso à informação [Internet]. 2020 [acesso em 2020 Abr 14]. Disponível em: http://www.hgf.ce.gov.br/index.php/categoria-1?cssfile=principal.css

18. Flick U. Pesquisa qualitativa: por que e como fazê-la. In: Flick UWE. Introdução à pesquisa qualitativa. 3rd ed. Porto Alegre: Artmed; 2009. p. 18-38.

19. Fontanella BJB, Ricas J, Turato ER. Amostragem por saturação em pesquisas qualitativas em saúde: contribuições teóricas. Cad Saúde Pública [Internet]. 2008 [acesso em 2020 Abr 9];24(1):17-27. Disponível em: http://www.scielo.br/scielo.php?script=sci_arttext\&pid=S0102-311X2008000100003

20. Bardin L. Análise de conteúdo. São Paulo: Edições 70; 2011.

21. Camargo BV, Justo AM. IRAMUTEQ: Interface de R pour les Analyses Multidimensionnelles de Textes et de Questionnaires. Temas Psicol [Internet]. 2013 [Acesso em 2020 Abr 9];21(2). Disponível em: http://pepsic. bvsalud.org/pdf/tp/v21n2/v21n2a16.pdf

22. Gomes ACD. Medicina e Religião no Hospital-Colónia Rovisco Pais. Coimbra: Universidade de Coimbra; 2014.

23. Fornazari AS, Ferreira RER. Religiosidade/espiritualidade em pacientes oncológicos: qualidade de vida e saúde. Psicol Teor Pesqui. 2010;26(2):265-272.

24. Di Primo AO, Schwartz E, Bielemann VLM, Burille A, Zillmeret JGV, Feijó AM, et al. Rede social e vínculos apoiadores das famílias de crianças com câncer. Texto \& Contexto Enferm. 2010;19(2):334-42.

25. Duarte FM, Wanderley KS. Religião e espiritualidade de idosos internados em uma enfermaria geriátrica. Psicol Teor Pesqui. 2011:27(1):49-53.

26. Almeida AS, Aragão NRO, Moura E, Lima GC, Hora EC, Silva LASM. Sentimento dos familiares em relação ao paciente internado na unidade de terapia intensiva. Rev Bras Enferm. 2009;62(6).

27. Passos SSS, Santos LM, Santos VMN, Santana VS, Silva JO, Pereira A. O acolhimento no cuidado à família numa unidade de terapia intensiva. Rev Enferm UERJ. 2015;23(3):368-74.

28. Blom H, Gustavsson C, Sundler AJ. Participation and support in intensive care as experienced by close relatives of patients: a phenomenological study. Intensive Crit Care Nurs. 2013;29(1):18.

29. Maestri E, Martins JJ, Nascimento ERP, Bertoncello KCG. Avaliação das estratégias de acolhimento na Unidade de Terapia Intensiva. Rev Esc Enferm USP. 2012;46(1):75-81.

30. Ministério da Saúde (BR). Portaria n.1707, 4 de julho de 2005. Dispõe sobre a Política Nacional de Atenção ao Paciente Crítico. Brasília: Ministério da Saúde; 2005.

31. Barros FE, Soares E, Teixeira MLO, Branco EMSC. Controle de infecção a pacientes em precaução de contato. Rev Enferm UFPE. 2019;13(4):1081-9.

32. Castro AF, Rodrigues MCS. Auditoria de práticas de precauções-padrão e contato em Unidade de Terapia Intensiva. Rev Esc Enferm USP. 2019;53:03508.

33. Santos HG, Santos CIL, Lopes DFM, Belei RA. Multirresistência bacteriana: a vivência de pacientes internados em Hospital-Escola do Município de Londrina - PR. Cienc Cuid Saude. 2010;9(1):74-8. 
34. Marques RB, Lovatto CG, Prevê CP, Souza SBC. A compreensão dos familiares de pacientes portadores de germes multirresistentes acerca do isolamento e das medidas de precaução. Rev Ciênc Saúde. 2014;7(3).

35. Freiberger MF, Silva DG, Pinheiro EC, Duarte RM, Santiago PO. Prevenção de infecção cruzada entre acompanhantes e pacientes em ambiente hospitalar. Rev Cient Fac Educ Meio Ambiente. 2011;2(Supl-I):74-6.

36. Stube M, Herman CTS, Benetti ERR, Stumm EMF. O enfermeiro na prevenção de infecções em terapia intensiva. Rev Enferm UFPE. 2013;7(esp):6989-97.

37. Beuter M, Brondani CM, Szareski C, Cordei FR, Roso CC. Sentimentos de familiares acompanhantes de adultos face ao processo de hospitalização. Esc Anna Nery. 2012;16(1).

38. Rabelo AHS, Souza TV. O conhecimento do familiar/acompanhante acerca da precaução de contato: contribuições para a enfermagem pediátrica. Esc Anna Nery. 2009;13(2):271-78.

39. Luiz FF, Caregnato RCA, Costa MR. Humanização na terapia intensiva: percepção do familiar e do profissional de saúde. Rev Bras Enferm. 2017;70(5):1095-103.

\author{
Autor para correspondência: \\ Lorena Guimarães Oliveira \\ Universidade de Fortaleza \\ Av. Washington Soares, 1321 \\ Bairro: Edson Queiroz \\ CEP: 60811-905 - Fortaleza - CE - Brasil \\ E-mail: lorena_4501@hotmail.com
}

Como citar: Oliveira LG, Monteiro GN, Azevedo VL, Barbosa AS, Girão CM, Studart RMB. A experiência vivenciada pelo familiar do paciente crítico em isolamento de contato. Rev Bras Promoç Saúde. 2020;33:10667. 